\title{
Prevalence of Human Papillomavirus (HPV) infection in women living in remote riverine communities in the Amazonas, Brazil
}

\author{
Marco Antonio Zonta ( $\sim$ mazonta09@gmail.com ) \\ Santo Amaro University https://orcid.org/0000-0002-9280-4270
}

\section{Karina Bonilha Roque}

Universidade de Santo Amaro

\section{Yara Juliano}

Universidade de Santo Amaro

\section{Anne Liljander}

Institute Experimental of Immunology, Euroimmun

\section{Markus Cavalar}

Institute Experimental of Immunology, Euroimmun

\section{Beatriz Ayumi Akaki}

Universidade de Santo Amaro

\section{Antonio Carlos Campos Pignatari}

Universidade Federal de São Paulo

\section{Carlos Robero Veiga Kiffer}

Universidade Federal de São Paulo

\section{Research article}

Keywords: cervical cancer, human papillomavirus, cytology, microarray, epidemiology

Posted Date: July 29th, 2019

DOl: https://doi.org/10.21203/rs.2.12030/v1

License: (1) This work is licensed under a Creative Commons Attribution 4.0 International License. Read Full License 


\section{Abstract}

Human papillomavirus (HPV) is the most common sexually transmitted infection worldwide. Since some HPV types are associated with the development of cervical cancer, routine screening for HPV plays a crucial part in cancer prevention programs at global level. In Brazil, the cervical cancer rate is among the highest in the world, in particular in indigenous women living in remote areas with limited access to public health services. The objective of this study was to determine the prevalence of HPV infections and their co-occurrence with cervical lesions in Brazilian women living in isolated riverine communities. Moreover, the association between social environment, sexual activity and prevalence of HPV infection was assessed.

\section{Background}

Cervical cancer is one of the most common cancers affecting women worldwide ${ }^{1}$ with $>85 \%$ of the cancer-related deaths occurring in low- and middle-income countries. The high mortality in these regions is often attributed to limited access to preventive measures such as regular cervical cancer screenings ${ }^{2}$. Although additional factors might contribute to the development of invasive cervical cancer, infection by certain high-risk human papillomavirus (HPV) types seem to be a prerequisite, with HPV type 16 and 18 accounting for approximately $70 \%$ of cervical cancers worldwide (Munoz et al 2004).

In Brazil, the highest incidence and mortality rates are found in regions with poor socioeconomic conditions ${ }^{1}$. According to the estimates for 2016 and $2017^{3}$ the incidence rate of cervical cancer is $37 / 100,000$ women in the state of Amazonas alone, ranking cervical cancer the leading malignancy in women. Furthermore, 16,370 new cases of cervical cancer per year nationwide have been estimated for 2018 and 2019 (15/100,000 women).

In the Brazilian Amazon, numerous indigenous communities live in remote areas with no or limited access to health care services, including cancer screening and treatment. Furthermore, low levels of education and low social status contribute further to the vulnerability of these remote populations. The situation is particularly difficult for women as services relating to family planning and reproductive and maternal health are often insufficient or not existent. Despite better accessibility to general health care services in urban areas, the Brazilian health system is precarious and does not prioritise disease prevention and general health promotions.

Pap smears (cytology) are often recommended for cervical cancer screening ${ }^{9}$. Until recently, however, these tests were only available at the referral centre in the state capital Manaus, thus limiting the accessibility for women living in the Amazon region. Additional factors related to cultural practices, fear of taking tests and lack of knowledge about the importance of cancer prevention further contribute to the low adherence to regular gynaecological examinations ${ }^{7,8}$. 
The "Doutores das Águas" Assistance Program, a non-governmental organisation created in 2011, is operating in the Amazon region, providing medical and dental care for these remote indigenous communities. In order to address the above mentioned issues the Women's Health Centre was introduced into the assistance program in 2017; providing women with comprehensive health assistance including cancer screening and detection of sexually transmitted infections (STIs).

In addition to cytology, and were accessible, methods for direct HPV detection are becoming increasingly important in the early diagnosis of cervical carcinomas. Through molecular HPV typing, women infected with high-risk types can be identified even before any pathological changes have developed.

Subsequently, by offering these women the possibility to participate in more frequent gynaecological screenings, the risk, and hence the rate of cervical cancer could be reduced substantially. However, knowledge regarding the epidemiology of intracervical epithelial abnormalities and HPV is scarce, in particular among indigenous women living in remote areas of Brazil. Therefore, the aim of this study was to determine the prevalence of cervical abnormalities and high/low risk HPV types in women living in riverine communities of the Amazon Basin. Furthermore, social and behavioural determinants, associated with an increased risk of HPV infections and cervical cancer development were investigated. The knowledge generated here will play a crucial part in the development and implementation of an improved women's health program.

\section{Methods}

\section{Ethical approval and informed consent}

Ethical approval was obtained from the ethics committee of Santo Amaro University São Paulo (Brazil Platform - CAAE: 61414216.4.0000.0081). Written informed consent was obtained from all study participants. For participants $<18$ years, the written consent was duly signed by the parents or guardians. The scheduling and recruitment of women, follow-up of collection procedures and organization of the site during the activities was supervised by the principal investigator while the sample collections were performed and supervised by the health team of the Women's Health Program. Women with cytological alterations received referral for further treatment by the responsible health agent from the local program.

\section{Study area and population}

The riverine populations investigated here inhabit the vast and complex waterways that are characteristic of the Amazon Biome, a set of ecosystems interconnected by the Amazon rainforest and the Amazon Basin. These communities share common characteristics such as economic and social isolation and exclusion from public services, basic health care and education ${ }^{10,11}$. Community leadership is predominantly female, although the family model is still patriarchal in communities further away from large centers. They live off traditional fishing, hunting and agricultural activities. Their houses are built on stilts near the riverbanks and lack electricity, piped water and basic sanitation. Rafts or boats are the only means of transport in this region. In a recent decree, the existence of these traditional peoples and 
communities was recognized, and a national policy, focused on improving the living conditions of these peoples was instituted ${ }^{13}$.

This cross-sectional study included women living in riverine communities along the two main tributaries of the Amazon River; Rio Madeira and Rio Negro and was performed in April 2017. All non-pregnant, nonmenstruating, sexually active women attending the gynecological clinic were invited to participate in this study. None of the women were vaccinated against HPV.

\section{Socio-demographic and clinical data}

Study participants were in-depth interviewed by a team of psychologists specialized in conducting gynecological anamnesis. The women were asked to answer questions regarding socio-demographic variables as well as behavioral/psychological determinants using a detailed questionnaire

\section{Sample collection}

The cervico-vaginal material was collected from the ectocervical (ectocervix and vagina) and endocervical regions using a standard cytobrush, then conserved in preservative medium (CellPreserv ${ }^{\mathrm{T}}$, Kolplast $^{\text {TM }}$ ci Ltda, Braziland stored at XX ${ }^{\circ} \mathrm{C}$ until further cytological and molecular analysis.

\section{Laboratory examination}

\section{Cytological analysis}

Cervical cell suspensions were fixed and processed using a KLP 2000 slide processor (Kolplast ${ }^{\mathrm{TM}}$ ci Ltda, Brazil) according to manufacturer's instructions. This was followed by Papanicolaou (Pap) staining and analysis by optical microscopy. The slides were analyzed by two experienced, blinded cytologists and classified according to the Bethesda system.

\section{HPV genotyping}

DNA was extracted from cervical cell suspensions using PureLink ${ }^{\mathrm{TM}}$ Microbiome DNA Purification kit (Invitrogen, USA) according to the manufacturer's instructions. DNA concentration and purity was determined using nanodrop ND-ONE-W (Invitrogen, USA). HPV genotyping was performed using EUROArray HPV (Euroimmun, Germany). Briefly, the HPV array is based on the detection of the viral oncogenes E6/E7 via multiplex PCR amplification and hybridization of the fluorescently labelled products with immobilized DNA probes. The use of type-specific primers and probes allows for simultaneous detection and typing of 30 anogenital high-risk $(n=18)$ and low-risk $(n=12)$ HPV types in one test run. Data 
analysis and interpretation was performed fully automated using the EUROArrayScan software according to the manufacturer's instructions.

\section{Data analysis}

Standard descriptive analyses were performed, including frequency distributions for categorical variables and calculation of means and standard deviations (SD). Contingency tables were analyzed by either chisquare tests $\left(\mathrm{X}^{2}\right)$ or Fisher exact tests using SPSS, version 20. The level of significance was 0.05 .

\section{Results}

In total 123 women from 9 different communities participated in the cervical sample collection. Sixty-five samples were from Rio Madeira communities; Cachoeirinha $(n=11)$, Canauini $(n=12)$, Itaquera $(n=10)$, Remanso $(n=12)$, Tanauau $(n=8)$ and Terra Preta $(n=12)$ and 58 samples were from Rio Negro communities; Arara $(n=30)$, Ariquemes $(n=12)$ and Bom Jardim $(n=16)$ of the Amazon basin (Figure 1.)

Results are based on data from 123 women unless stated otherwise. The mean age of the participating women was 33.7 ( \pm 13.4 ) years, ranging from 14 to 78 years (based on data from 119 women). Almost half $(n=59,48.0 \%)$ of the women were illiterate or had only completed elementary school, $52(42.3 \%)$ had finished high school, and twelve women $(9.7 \%)$ had a college education. The majority of women enquired reported either not to be working $(n=34,27.6 \%)$ or being a farmer $(n=39,31.7 \%)$. Furthermore, most women $(84.5 \%)$ reported living off less than one minimum wage. In total 10 women (8.1\%) reported using tobacco (smoking).

The women were on average $14.9( \pm 2.8)$ years at sexarche (based on data from 122 women) and 17.5 ( \pm 3.8) years old at first pregnancy (based on data from 90 women). In total 105 (86.1\%) of the women had children and nearly half of them $(n=52,49.5 \%)$ had 4 or more (range 1 to 14 , based on data from 122 women). Furthermore, most of the women ( $n=99,80.5 \%)$ were married or living with a partner. Sixteen women (13.1\%) reported using condoms.

The women living in the Rio Madeira communities had fewer lifetime sexual partners than the women living in the communities in the Rio Negro area (Table 1., $p<0.001$ ). There were no other significant differences in socio-demographical or behavioural variables between women from the two regions (Table 1.); hence subsequent analyses regarding risk factors and HPV prevalence were performed for all women combined.

\section{Cytological evaluation}

Among the 121 cervical smear samples considered suitable for cytopathological evaluation, the overall prevalence of epithelial cell abnormalities amounted to $9.9 \%$ (Table 2.). The average age of the women presenting with cervical abnormalities was 41.6 years (range 19 to 63 years). Among the 109 samples 
$(90.1 \%)$ that were negative for intraepithelial lesions or malignancies, 9 showed no reactive alterations in cellular morphology (classified as normal), while the rest were classified as reactive, compatible with inflammation (Table 2.). The reactive samples $(n=100)$ all exhibited patterns of cell alteration associated with infection by pathogens such as Candida spp and/or bacterial vaginosis (Table 3 ). The abnormal smears included 2 samples (1.7\%) with atypical squamous cells of undetermined significance (ASC-US), 5 samples (4.1\%) with low-grade squamous intraepithelial lesions (LSIL) and 5 samples (4.1\%) with highgrade squamous intraepithelial lesions (HSIL). There were no significant differences in the prevalence of intraepithelial lesions or inflammatory infiltrates between the two regions $(p=0.5)$.

\section{HPV infection prevalence}

The overall HPV prevalence amounted to $25.4 \%$. There was no significant difference in HPV infection prevalence between the two regions $(p=0.4)$. Infections with multiple HPV types were more common in women from Rio Madeira compared to women from Rio Negro ( $57.1 \%$ vs. $17.6 \%, p=0.03)$. Infections with 5 to 7 different HPV types were detected. The type distribution was broad with, in total of 22 different types detected (Figure 2.); 17 in the Rio Madeira and 13 in the Rio Negro women, with HPV 16 (19.4\%), HPV 31 (12.9\%), HPV 45 (12.9\%) and HPV 53 (12.9\%) being the most common types. Two women tested positive for HPV 18. Among the 12 women presenting with any intraepithelial abnormalities (ASC-US, LSIL and HSIL), 4 were infected with HPV. Two of them were from Rio Madeira; one presenting with LSIL in association with concomitant infection with HPV types 43, 53 and 72 while the second woman had HSIL and was infected with HPV types 51 and 39. The other 2 women were from Rio Negro; one presented with LSIL in association with HPV type 61 and one, presenting with ASC-US, was infected with HPV 61. For the 8 remaining women with abnormal smears, no HPV infections were detected. None of the women infected with high-risk HPV type 16 and/or 18 presented with cervical abnormalities besides signs of inflammation.

\section{Determinants of risk factors for HPV infections}

Among all women, the prevalence of HPV infections was significantly higher in women younger than 25 years $(41.0 \%)$ and women older than 50 years (31.3\%) compared to women between 26 and 49 years (14.3\%) ( $p=0.006$, based on data from 118 women). HPV infections were more common in single (42.1\% infected) than in married women (21.4\% infected) but the difference was however not significant. Moreover, the sexarche was not associated with HPV prevalence $(p=0.6)$. In total $27.7 \%$ of the women that had first sexual intercourse at the age of 15 years or less were infected with HPV, while $21.1 \%$ were HPV positive in the group of women older than 16 years at sexarche (based on data from 121 women). No significant associations between income ( $\leq 1$ salary vs. $>1$ salary), number of lifetime sexual partners $(1,2-3$, or $\geq 3)$, condom use, smoking or parity $(0,1-3$ or $>3)$ and prevalence of HPV infection were found (Table 5.).

\section{Discussion}


The Amazonas state in northern Brazil is an area with a high incidence rate of cervical cancer ${ }^{14}$. Most previous studies have investigated the prevalence of cervical abnormalities and HPV infections in urban populations (REF). Consequently, the knowledge regarding these conditions in women living in remote indigenous communities is still largely lacking. Here, the prevalences of epithelial cell abnormalities and HPV infections were investigated in 123 women living in 9 remote riverine communities of the Amazon basin. These communities are characterized by a low level of education with almost half the women $(48 \%)$ not being able to read or write or only having finished elementary school.

A relatively high rate of cervical abnormalities was found with almost $10 \%$ of the women displaying cytological alterations (Table 2.). This rate is similar to what has previously been reported from the Brazilian state of Paraná where $10.7 \%$ of the women had cellular atypia (REF NR 22). Lower prevalences, ranging between 2.1\% to 3.3\%, have however been described in other areas of Brazil (Rocha et al 2013, REF NR 17 and Coser et al 2013). Moreover, cytology also showed a large percentage (81.3\%) of reactive changes associated with inflammation, a prevalence that corroborates the results obtained in other studies from Amazonian communities in Brazil 7,23. Microscopic examination showed signs of infection with Candida spp and/or bacterial vaginosis. However since the presence of other sexually transmitted diseases (STDs), also known to cause local inflammation e.g. chlamydia (ref IARC and Lehtinen et al 2011) and herpes simplex virus infections (IARC) was not investigated, other causes cannot be excluded. Other STDs e.g. Trichomonas vaginalis and Gardnerella vaginalis have also been associated with HPV and cervical lesion progression (Amorin et al), hence, future studies should include screening for additional co-infecting agents.

Differences in reported frequencies of cervical abnormalities and/or HPV infections as well as in the types of circulating viruses emphasize the importance of assessing regional as well as population heterogeneities in order to develop suitable disease prevention programs. Hence, direct detection and typing of HPV using molecular techniques is often used as a supplement to cytology for routine cervical cancer screening (Levi et al 2019). Overall HPV prevalences ranging between $14.3 \%$ and $65.2 \%$ have previously been reported in Brazil and elsewhere in South America (Clifford et al 2005, South America, SanJose et al 2007), Rocha et al, Coser et al, Lippman et al 2010, Fonseca et al, Fernandes et al 2013). Here, 31 of the $122(25.4 \%)$ investigated women were infected with HPV, $6(19.4 \%)$ of them were positive for HPV 16; ere $14.3 \%$ of the Rio Madeira women and $23.5 \%$ of the Rio Negro women, thus making type 16 the most commonly detected. This is similar to what had previously been reported (Fernandes et al 2013, Lippman 2010, Coser et al, REF18). In addition, HPV 31, 45 and 53 were also frequently detected while HPV 18 was less common with only two women being positive. 
Using a DNA microarray, in total 22 different HPV types; 14 high-risk HPV $(16,18,31,33,35,39,45,51$, 52, 53, 56, 58, 59 and 66) and 8 low-risk $\operatorname{HPV}(6,42,43,44,54,61,72$ and 81) were differentiated; 17 types among the Rio Madeira women and 13 types among the Rio Negro women. Regional diversity in the circulating HPV types has previously been described; six HPV types were identified in Manaus, Brazil (Castro et al 2011, 14 in the city of Coari, Brazil (Rocha et al) while more than 60 were detected in the Amazonian rainforest (Fonseca et al 2015). Here, cervical intraepithelial lesions were related to HPV 43, 53 and 72 (LSIL), and HPV 39, 51 and 61 (HSIL). Furthermore, one woman with ASC-US was infected with HPV 61. Even though none of the women infected with HPV 16/18 presented with atypia, the high prevalence of HPV 16, 31 and 45 infections in the study populations highlights the importance and correspondingly the probable health gains of introducing HPV vaccination in these remote regions.

In addition to HPV, there are other risk factors predisposing to the development and progression of cervical dysplasia such as multiple sexual partners, early sexarche, HIV infection, other STDs, multiparity, smoking and taking oral contraceptives. Here, eight cases of cervical intraepithelial lesions with no HPV present were identified. Besides the above-mentioned factors contributing to the atypia the possibility that rare HPV types, not tested for here, are circulating in the region (REF Fonesca et al 2015), can however not be excluded. In addition, 27 cases of high- and low-risk HPV infection without the manifestation of cervical intraepithelial lesions were identified. These infections are likely to resolve spontaneously. Nonetheless, affected women should be continuously monitored for disease progression.

The association between social and behavioural factors and HPV prevalence was investigated. The women's age was associated with the prevalence of HPV infection $(p=0.006)$, with infections being more common in women aged 25 years or less and 50 years or more when compared to women aged 26 to 49 years. Similar age-dependent patterns have previously been described ${ }^{29}$,. The higher prevalence in older women could possibly be due to reactivation of latent infections due to the gradual loss of type-specific immunity or changes in the pattern of sexual behaviour over the age ${ }^{30}$.

In total $8,1 \%$ of the women were smokers. There are divergences in the literature regarding smoking and increased susceptibility to HPV infections; however, it has been implicated as a cofactor associated for the development of high-risk lesions (HSIL) and cervical carcinoma (REF). Furthermore, smoking appears to increase cervical and systemic susceptibility to general infections and HPV ${ }^{6,24}$. Here, however, the relationship between smoking and the prevalence of HPV infections was not statistically significant (Table 5.). Similarly, condom use was not significantly associated with HPV prevalence. Even though the overall condom use was rather low here (13.1\%), the results corroborates the literature which states that sexual contamination can only be avoided through complete sexual abstinence, since condoms do not guarantee full protection and the virus can still be transmitted via non-penetrative sex. In addition, 
different variables influence condom use such as age, number of sexual partners, knowledge of correct use, accessibility, partner age and the ability to negotiate condom use with partner. ${ }^{25,26}$

Furthermore, the sexarche was not significantly associated with HPV prevalence, thus contradicting literature which considers early sexual initiation as a factor related to a larger number of sexual partners, favouring the acquisition of STDs and early pregnancy ${ }^{32}$. In addition, as shown previously, early onset of

sexual activity and teenage pregnancy increase the risk of developing cervical cancer ${ }^{33}$. Furthermore, the literature states that having multiple sexual partners is a risk factor for contracting HPV ${ }^{35,36}$. Here, the Rio Negro women had significantly more sex partners than the Rio Madeira women (average 6 vs. 1, $p<0.001$ ), there was however no significant association between the number of lifetime sexual partners and the prevalence of HPV (Table 5.). Furthermore, more single women were infected with HPV compared to married women in this study, but the difference was not significant. Previous studies have also associated high parity as a factor for cervical carcinogenesis ${ }^{37,38}$. Here, HPV was more prevalent in women that never have had children compared to multiparous women; the difference was however not significant and likely associated with that these women were younger.

\section{Conclusion}

Here we have shown that indigenous women living in remote communities near the Rio Madeira and the Rio Negro tributaries of the Amazon River, are frequently infected with high-risk HPV and are is such at a risk of developing intraepithelial lesions which could result in neoplastic transformation and cervical cancer. Notably, almost $10 \%$ of the women investigated here displayed cervical epithelial abnormalities. Furthermore, although not significantly associated with HPV infection prevalence in this study, risk factors and behaviours such as low level of education, early sexarche and early pregnancy, low condom use, high parity and high number of sexual partners (Rio Negro area only) characterized these populations. In addition, the high prevalence of cellular alterations associated with inflammation; suggestively due to other infectious agents further emphasizes the importance of an extended monitoring to further characterize the prevalence of infections of gynaecological importance in the region.

\section{Declarations}

\section{Ethics approval and consent to participate}

Consent for publication

\section{Availability of data and material}

\section{Competing interests}


AL and MC are employees of EUROIMMUN AG. The authors have declared no competing interest in this study.

\section{Funding}

\section{Authors' contributions}

\section{Acknowledgements}

We thank Anna-Lena Hickmann and Viola Borchardt-Lohölter for their valuable comments and contributions to the manuscript

\section{Authors' information (optional)}

\section{References}

1. NETO, J.A.C. et al. Parental attitude about vaccination of their daughters against HPV to prevent cervical cancer. Cadernos Saúde Coletiva, v. 24, n. 2, p. 248-251, 2016. 2. SILVA, M.R.F. et al. Continuidade Assistencial a mulheres com câncer de colo de útero em redes de atenção à saúde: estudo de caso, Pernambuco. Saúde debate, v. 40,n. 110, p. 107-119, 2016 3. INCA. Sistema de câncer de base populacional [on-line]. Incidência de câncer de colo de útero Manaus e Amazonas. 2016. 4. INCA. Sistema de câncer de base populacional [on-line]. 2018. Disponível em: 5. Matos, E.; Loria, D.; Amestay, G.M.; Herrera. L; Prince, M.A.; Morena, J. et al. Prevalence of human papillomavirus infection among woman in Concórdia, Argentina: a population-based study. Sex Transm Dis. 2003 Aug; 30 (8): 593-9 6. Goodman, M.T; Shvetson, Y.B; McDuffie, K; Wilkens, L.R; Zhu, X; Thompson, P.J. et al. Prevalence, acquisition, and clearance of cervical human papillomavirus infection among woman with normal cytology: Hawaii Human Papillomavirus Cohort Study. Cancer Res, 2008, 68 (21): 8813-24 7. Taborda, W.C.; Ferreira, S.C.; Rodrigues, D.; Stavale, J.N; Baruzzi, R.G. Cervical cancer screening among indigenous women in the Xingu Indian Reservation, central Brazil. Rev. panamer. Salud publ., 7: 92-96, 2000. 8. Clifford GM, Gallus S, Herrero R, Munoz N, Snijders PJ, et al. Worldwide distribution of human papillomavirus types in cytologically normal women in the International Agency for Research on Cancer HPV prevalence surveys: a pooled analysis. Lancet. 2005;366:991-8 9. Castro, M. M.; Farias, I. P.; Santos, C. M. B.; Correia, G.; Filho, S. A. "Prevalence of human papillomavirus (HPV) type 16 variants and rare HPV types in the central Amazon region," Genetics and Molecular Research, vol. 10, no.1, pp. 186-196, 2011. 10. FRAXE, Therezinha de Jesus Pinto; PEREIRA, Henrique dos Santos; WITKOSKI, Antônio Carlos. Comunidades ribeirinhas amazônicas: modos de vida e uso dos recursos naturais. Manaus: EDUA, 2007. 11. Lima, LIMA, Maria Aldecy Rodrigues de Lima; ANDRADE, Erika dos Reis Gusmão. Os ribeirinhos e sua relação com os saberes. Revista Educação em Questão, Natal, v. 38, n. 24, p. 58-87, maio/ago. 2010. Disponível em: . Acesso em: 27 maio 2014. 12. RIBEIRINHOS da Amazônia. In: PORTAL da Amazônia. Disponível em: . Acesso em: 27 maio 2014 13. BRASIL. Decreto 6.040 de 7 de fevereiro de 2007. Disponível em: . Acesso em: 26 maio 2014 14. Silva, J.A.G. Estimativa 2012: Incidência de Câncer no Brasil, Instituto Nacional do Câncer, Rio de Janeiro, Brazil, 2011. 15. Clifford GM, Gallus S, Herrero R, 
Munoz N, Snijders PJ, et al. Worldwide distribution of human papillomavirus types in cytologically normal women in the International Agency for Research on Cancer HPV prevalence surveys: a pooled analysis. Lancet. 2005;366:991-8. 16. Torres, L.M; Páez, M.; Insaurralde, A.; Rodriguez, M.I.; Castro. A.; Kasamatsu, E. Detection of high risk human papillomavirus cervical infections by the hybrid capture in Asunción, Paraguay. Braz J Infect Dis. 2009 Jun; 13 (3): 203-6 17. Fonseca, A.J; Taeko, D; Chaves, T.A; Amorim, L.D; Murari, R.S; Miranda, A.E; Chen, Z; Burk, R.D; Ferreira, L.C. et al. HPV Infection and Cervical Screening in Socially Isolated Indigenous Women Inhabitants of the Amazonian Rainforest. PLoS One. 2015; 10(7):e0133635. doi:10.1371/journal.pone.0133635. eCollection 2015. 18. Castro, M. M.; Farias, I. P.; Santos, C. M. B.; Correia, G.; Filho, S. A. "Prevalence of human papillomavirus (HPV) type 16 variants and rare HPV types in the central Amazon region," Genetics and Molecular Research, vol. 10, no.1, pp. 186196, 2011. 19. Oliveira, M.M.H.N.; Silva, A.A.M.; Brito, L.M.O.; Coimbra, L.C. Cobertura e fatores associados à não realização do exame preventivo de Papanicolaou em São Luís, Maranhão. Rev Bras Epidemiologia 2006; 9(3):325-334 20. Bolpetti, A.; Silva, J.S.; Villa, L.L.; Lepique, A.P. Interleukin-10 production by tumor infiltrating macrophages plays a role in Human Papillomavirus 16 tumor growth. BMC Immunol. 2010; 11:27 21. Gardelha, S.R.; Soares-Barreto, D. M. V.; Costa, G. B.; Leal, V. C. N.; Gomes, L. G. S.; Santos, U. R.; Ferreira, G. C. S.; Carvalho, L. D.; Soares-Almeida, S. M. V.; Mello, M. A. G.; Mariano, A. P. M.; Sousa, S. M. B.; Vago, A. R.; Marin, L. J. Clinical, laboratory and epidemiological aspects of HPV infection in a lowincome population from South Bahia, Brazil. Disponível em:

https://doi.org/10.1017/S0950268817002448. Published online: 23 November 2017 22. Rodrigues, D.A.; Pereira, E.R.; Oliveria, L.S.S.; Speck, N.M.G.; Gimeno, S.G.A. Prevalence of cytological atypia and high-risk human papillomavirus infection in Panará indigenous women in Central Brazil. Cad. Saúde Pública vol.30 no.12 Rio de Janeiro Dec. 2014. Disponível em: http://dx.doi.org/10.1590/0102-31/'1X00152713 23. Brito, E.B.; Menezes, R.C.; Martins, S.J.; Bastos, M.G; Sousa, A. Preliminary study on low-trait genital infection and cervical epithelial dysplasia in women from the Parakana tribe of South America. Rev. Ass. méd. bras., 42:11-15, 1996 24. Basemann, J.G; Koustky, L.A. The epidemiology of human Papillomavirusvirus infections. J Clin Virol, 2005;32 suppl 1: 16-24 25. NADAL, L. R. M.; NADAL, S. R. Indicações da vacina contra o papilomavirus humano. Indications for human papillomavirus vaccination, Rio de Janeiro - RJ, v. 28, n. 1, Janeiro/Março, 2008 26. Shrier LA, Goodman E, Emans SJ. Partner Condom Use Among Adolescent Girls with Sexually Transmitted Diseases. Journal of Adolescent Health. 1999; 24: 357-61 27. Rodríguez Ml. Conocimientos y actitudes de las mujeres sobre la prevención del cáncer de cuello uterino, San Lorenzo - 2008. Universidad Nacional de Asunción. 2009 pp. 12828. Trottier, H.; Franco, E.L. "The epidemiology of genital human papillomavirus infection," Vaccine, vol. 24, supplement 1, pp. S4-S15, 2006 29. Diaz, S.M.S; Castellsangu'e, X. et al., "Worldwide prevalence and genotype distribution of cervical human papillomavirus DNA in women with normal cytology: ametanalysis," The Lancet Infectious Diseases, no. 7, pp. 453-459, 2007 30. Fredizzi, E.M; Schlup, C G; Menezes, M. E; Ocampos, M. "Human Papillomavirus (HPV) infection in women of Florian 'opolis, Santa Catarina, Brazil," Jornal Brasileiro de Doenças Sexualmente Transmissiveis, vol. 20, no. 2, pp. 73-79, 2008 31. Bruni, L.; Diaz, M.; Castellsague, X.; Ferrer, E.; Bosch, F.X.; de Sanjose S. Cervical human papillomavirus prevalence in 5 continents: meta-analysis of 1 million women with normal cytological findings. J Infect Dis. 2010; 202: 1789 \pm 1799 . doi: 10.1086/657321 PMID: 21067372 32. Vinodhini K, 
Shanmughapriya S, Das BC, Natarajaseenivasan K. Prevalence and risk factors of HPV infection among women from various provinces of the world. Arch Gynecol Obstet. 2012; 285: 771 \pm 777 . doi:

10.1007/s00404-011-2155-8 PMID: 22159694 33. Louie, K.S; de Sanjose, S.; Diaz, M.; Castellsague, X.; Herrero, R.; Meijer, C.J. et al. Early age at first sexual intercourse and early pregnancy are risk factors for cervical cancer in developing countries. Br J Cancer. 2009; 100: 1191士1197. doi: 10.1038/sj.bjc.6604974 PMID: 19277042 34. Hwang, L.Y; Ma, Y.; Benningfield, S.M; Clayton, L.; Hanson, E.N; Jay, J. et al. Factors that influence the rate of epithelial maturation in the cervix in healthy young women. J Adolesc Health. 2009; 44: 103 \pm 110 . doi: 10.1016/j.jadohealth.2008.10.006 PMID: 19167657 35. Vinodhini K, Shanmughapriya S, Das BC, Natarajaseenivasan K. Prevalence and risk factors of HPV infection among women from various provinces of the world. Arch Gynecol Obstet. 2012; 285: 771 \pm 777 . doi:

10.1007/s00404-011-2155-8 PMID: 22159694 36. Páez M, Rodríguez-Riveros MI, Kasamatsu E, Castro A, Orué $\mathrm{E}$, Lampert $\mathrm{N}$, et al. Conocimientos, actitudes y prácticas sobre virus de papiloma humano (VPH) y cáncer de cuello uterino en mujeres de 30 y más años de edad, de un barrio ribereño de Asunción, (Bañado Sur). 2012. Rev Univ Ind Santander Salud. 2016; 48(1): 37-44. DOI:

http://dx.doi.org/10.18273/revsal.v48n1-2016004 37. Hildesheim A, Wang SS. Host and viral genetics and risk of cervical cancer: a review. Virus Res 2002; 89:229-40 38. Muñoz N, Franceschi S, Bosetti C, Moreno V, Herrero R, Smith JS, et al. Role of parity and human papillomavirus in cervical cancer: the IARC multicentric case-control study. Lancet 2002; 359:1085-92

\section{Figures}

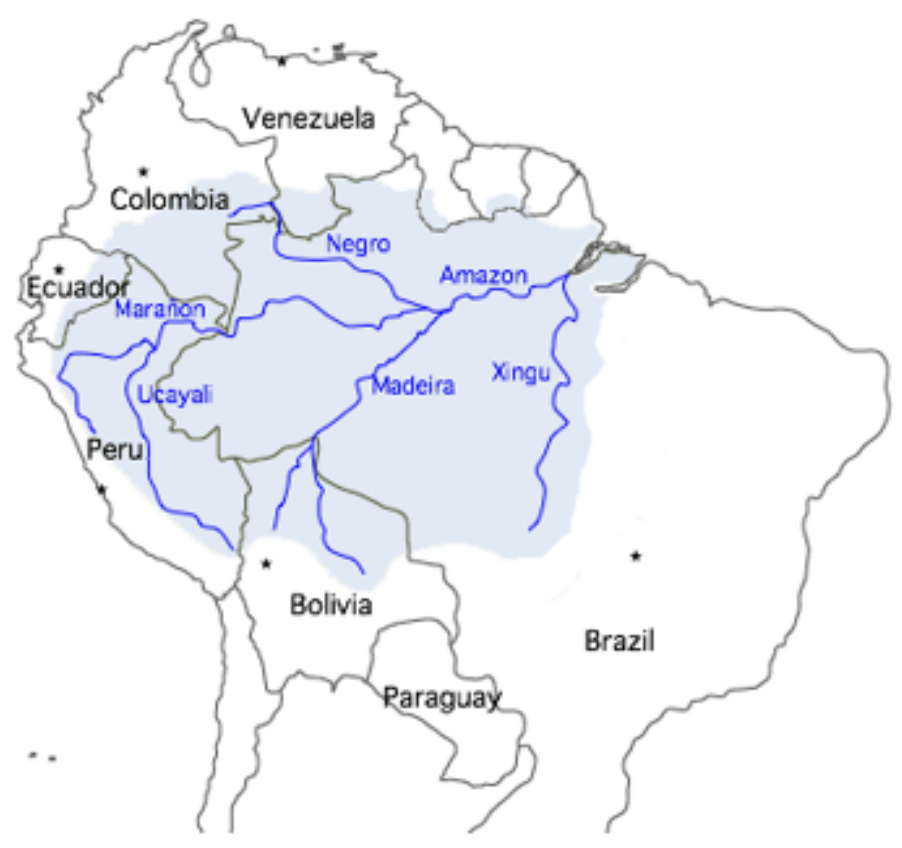

Figure 1 
Map depicting the location of Rio Madeira and Rio Negro in the Amazon basin.

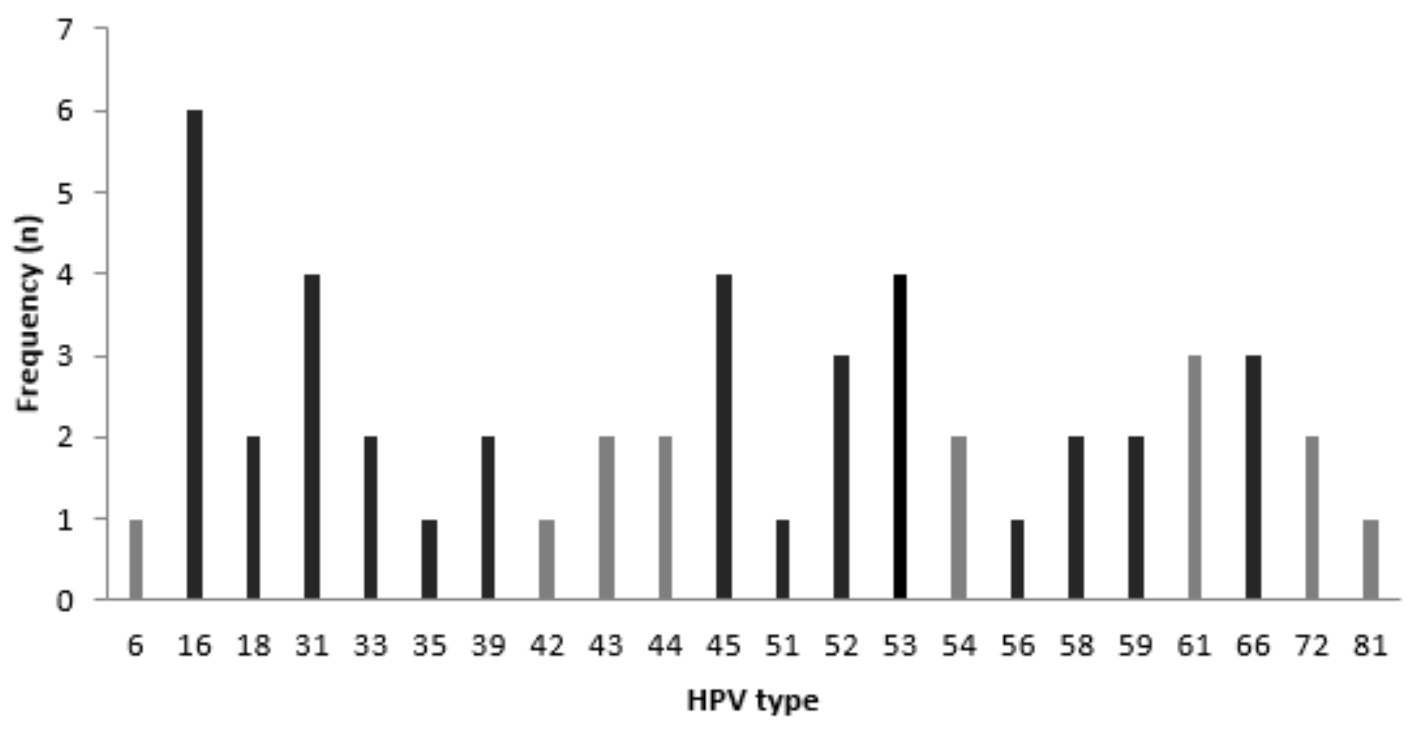

\section{Figure 2}

Frequency of HPV types in the study population ( $n=121)$. HPV types with high oncogenic risk are depicted in black.

\section{Supplementary Files}

This is a list of supplementary files associated with this preprint. Click to download.

- Tables.pdf 